\title{
A Geometria Elementar e Intuitiva de Gabriel Prestes
}

\section{The Elementary and Intuitive Geometry of Gabriel Prestes}

\author{
Maria Célia Leme da Silva
}

Universidade Federal de São Paulo - GHEMAT. SP, Brasil. E-mail: celia.leme@unifesp.br

\begin{abstract}
Resumo
O presente estudo tem a intenção de compreender como Gabriel Prestes, considerado um expert (Hofstetter et al, 2017) da educação, por ocupar lugar de destaque na direção da Escola Normal de São Paulo, propõe o ensino de uma geometria escolar. A análise toma como fonte central o manual Noções Intuitivas de Geometria Elementar produzido por Prestes e publicado em 1895. O exame do manual fornece indícios de proposta inovadora: proximidade com a obra francesa de Paul Bert (1886), inversão na marcha dos conteúdos tradicionalmente apresentados ao propor um estudo direto das medidas de linhas, áreas e volumes para o segundo ano primário, uso de materiais como fios, barbantes, papelão, recortes de papel, construção de sólidos para um trabalho experimental, de comparação e discussão das medidas, o emprego do desenho à mão livre como auxiliar nas recapitulações. Entretanto, a perda de poder político e o afastamento de Gabriel Prestes da Educação são fatores que corroboram para que a sua proposta de uma geometria intuitiva não tenha feito escola.
\end{abstract}

Palavras-chave: Taquimetria. História do Ensino de Geometria. Grupos Escolares de São Paulo. Século XIX.

\begin{abstract}
The present study intends to understand how Gabriel Prestes, considered an expert (Hofstetter et al, 2017) of education, to occupy a prominent place in the direction of the Normal School of São Paulo, proposes the teaching of a school geometry. The analysis takes as its central source the Manual Notions Intuitive of Elementary Geometry produced by Prestes and published in 1895. The examination of the manual provides indications of an innovative proposal: proximity to the French work of Paul Bert (1886), reversal of the traditionally presented contents by proposing a direct study of the measurements of lines, areas and volumes for the second primary year, use of materials such as yarn, string, paperboard, paper cutting, solids construction for experimental work, comparison and discussion of measures, employment of freehand drawing as an aid in recapitulations. However, the loss of political power and the removal of Gabriel Prestes from Education are factors that corroborate so that his proposal of an intuitive geometry did not make school.
\end{abstract}

Keywords: Tachymetry. History of Geometry Teaching. School Groups in São Paulo. XIX Century.

\section{Introdução}

O estudo desenvolvido por Leme da Silva et al (2017) reuniu um número significativo de manuais escolares publicados no final do século XIX e início do século XX no sentido de realizar uma primeira caracterização dos saberes matemáticos ${ }^{1}$ nos manuais escolares durante a denominada vaga intuitiva² e identificou a obra de Gabriel Prestes (1895) como candidata a ocupar o papel de manual inovador (Chervel, 1990) no que diz respeito aos saberes geométricos ${ }^{3}$ e à taquimetria ${ }^{4}$.

O presente estudo tem a intenção de aprofundar a análise do manual de modo a compreender como Gabriel Prestes, considerado um expert da educação (Hofstetter et al., 2017), ocupando lugar de destaque na direção da Escola Normal de São Paulo, propõe o ensino de uma geometria escolar. O manual intitula-se Noções Intuitivas de Geometria Elementar e foi publicado em 1895. A partir dos pressupostos da história cultural, o estudo considera o manual escolar como objeto cultural produzido no contexto brasileiro do final do século XIX, marcado pela circulação de ideias francesas na área da educação brasileira de modo a legitimar as propostas inovadoras (Bastos, 2000).

\footnotetext{
1 Os saberes elementares matemáticos são entendidos como os primeiros passos, a base inicial de conhecimentos em matemática organizada para ser ensinada aos alunos dos primeiros anos escolares, em consonância com as vagas pedagógicas a que fica submetido o sistema escolar (Valente, 2015).

2 Designa-se por vaga intuitiva a periodização estabelecida por historiadores da educação, como Pedagogia Moderna (Carvalho, 2000), Método do ensino intuitivo ou Lições de coisas (Valdemarin, 2004), Ensino ativo (Vidal, 2006).

3 Opta-se por usar o termo saberes geométricos, entendendo-o como os conceitos, definições, temas, propriedades e práticas pedagógicas relacionadas à geometria que estejam presentes na cultura escolar primária

4 "A taquimetria é a concretização da geometria, é o ensino da geometria às inteligências mais rudimentares: é a lição de coisas aplicada à medida das extensões e volume.” (Barbosa, Tomo II, 1946, p. 290).
} 


\section{Escola Normal de São Paulo}

Dois de agosto de 1880 é a data da reabertura definitiva da Escola Normal de São Paulo. Trata-se da "terceira fase" com regimento próprio, diretor subordinado ao presidente da província e congregação de professores. A cidade de São Paulo, na década de 1880, consolida seu caráter urbanocapitalista, passa por metamorfoses, torna-se conglomerada e cosmopolita, concentrando as funções de capital política, econômica e cultural da província (Monarcha, 1999).

A Escola Normal inicia seu funcionamento em 1880 com o número de 61 matriculados e nove anos mais tarde, em 1889 , conta com 339 alunos. A organização didático-pedagógica do programa de 1880 para a formação de professores primários organiza-se em dez matérias distribuídas em cinco cadeiras, sendo a segunda, destinada à Aritmética e Geometria, sob a responsabilidade do Dr. Godofredo José Furtado ${ }^{5}$.

Os documentos administrativos, como atas das reuniões da congregação, ofícios e relatórios anuais, registram tensões e conflitos ideológicos entre professores, diretores e presidentes da província. Durante 1884 a 1887, a situação interna agrava-se, em especial por conta de um grupo de professores ortodoxos $^{6}-$ Antonio Silva Jardim 7 , Godofredo José Furtado e Cypriano José de Carvalho que representam o positivismo na Escola Normal de São Paulo:

Através de intervenções prático-teóricas, escritas e faladas (conferências, aulas, ofícios, folhetos), os professores ortodoxos produzem, expandem e colocam em circulação a ideia de educação positiva fundada em uma didática estruturada na perspectiva de síntese histórica, concebida como: reunião de elementos concretos e abstratos em um todo relacional e produção de um ponto de vista superior, objetivando a economia da vida mental, substituindo-se a síntese espontânea pela sistemática (Monarcha, 1999, p. 152).

Em 1889, ano da Proclamação da República, os alunos da Escola Normal saem às ruas saudando a República:

Para os instituidores da República, a instrução popular - a Escola Normal e a instrução primária - é um centro multiplicador das luzes, que colocam as ideias em marcha, impulsionando a história em direção ao progresso e à liberdade.

Em outras palavras, a ordenação do conhecimento em uma perspectiva de síntese científica é a condição crucial para a irradiação das luzes (Monarcha, 1999, p. 172).

\section{A Nova Escola Normal e Gabriel Prestes}

Em dois de agosto de 1894, 14 anos depois da reabertura da Escola Normal, é inaugurado o novo edifício destinado a abrigar o Curso Normal de São Paulo ${ }^{8}$.

A localização do novo edifício da Escola Normal de São Paulo em uma praça pública - aparentemente predomínio do poder temporal sobre a autoridade espiritual - é indicativo da fusão entre o secular e o religioso, originando uma quase religião cívica, presidida por sacerdotes laicos, a qual se instala e se expande na cultura escolar urbana paulista da virada do século (Monarcha, 1999, p. 187).

A Escola Normal, que passa então a ser designada por Escola Normal da Praça e tem no cargo de diretor da instituição Gabriel Prestes. Prestes (1867-1911) foi aluno na Escola Normal entre 1886 e 1888, elegeu-se deputado pelo Partido Republicano Paulista em 1891 e em 1893 foi responsável pela reforma republicana da instrução pública (Souza, 2009). Monarcha analisa a sua atuação na direção:

A gestão administração de Gabriel Prestes (1893-1898) - representa o "período áureo da instrução pública paulista". Formado pela Escola Normal, "positivamente educado" Prestes coloca termo às flutuações do instituto", exercendo quase plena ditadura espiritual" sobre a Escola Normal (Monarcha, 1999, p. 201).

Gabriel Prestes, ao assumir o cargo de diretor da Escola Normal, integra, de maneira efetiva, o grupo de responsáveis pela implementação, em São Paulo, das novas propostas pedagógicas que circulam no Brasil do final do século XIX e que toma a Escola Normal como um modelo de formação de professores:

A organização de uma Escola Normal é, por sua natureza, extremamente complexa. A formação de professores baseiase num curso teórico, que tem forçosamente de acompanhar, nos seus elementos, a evolução da ciência contemporânea, e num tirocínio prático, que, para ser completo, pressupõe a existência de instituições de ensino primário e integral nos seus dois elementos constitutivos: educação e ensino. Não se trata, pois, de simples organização de uma escola especial; trata-se de uma escola teórica e profissional que resume em si todas as instituições do ensino público, e que nos seus elementos constituintes sintetiza todo um sistema de instrução (Prestes, 1896, p.3-4 apud Monarcha, 1999, p. 206).

$\mathrm{Na}$ análise do historiador Carlos Monarcha, a direção de Gabriel Prestes à frente da Escola Normal legitimou a organização de um programa de estudos "lógica e

5 "Godofredo José Furtado nasce em 1851, filho do Conselheiro Francisco José Furtado, por várias vezes deputado e senador pelo Maranhão. Estuda engenharia na Escola Central do Rio de Janeiro, dá aulas de Física e Matemática como preparador nessa Escola, ao formar-se trabalha na comissão de levantamento da carta geral do Brasil. A partir de divergências com políticos do Império, afasta-se do emprego público e dedica-se ao magistério particular, como professor de matemática" (Valente, 2011, p. 40).

6 De acordo com Monarcha (1999) “A convição científica popularizada pelos ortodoxos visa esclarecer a opinião pública sobre a nossa origem e destino comuns. Propõem a Paz Universal mediante o aperfeiçoamento de nossa situação material, através da indústria, e o aperfeiçoamento de nossa moral, através da educação positiva, difundindo uma interpretação pedagógica da realidade brasileira amplamente compartilhada pelos sujeitos esclarecidos da época" (p. 126).

7 Em 1881, na capital da província de São Paulo, Miguel Lemos, diretor do positivismo no Brasil, pronuncia nove conferências abordando a vida e obra de Comte e o positivismo no Brasil, além de participar ao lado de Antonio da Silva Jardim da fundação do Centro Positivista de São Paulo. Em 15 de setembro, a Sociedade Positivista de São Paulo foi definitivamente fundada sob a presidência do Sr. Godofredo Furtado (Monarcha, 1999).

8 "Escola Normal da Praça é a denominação afetiva dada pelos contemporâneos da época à Escola Normal de São Paulo, destinado a abrigar o Curso Normal, a Escola-Modelo Preliminar Antonio Caetano de Campos, a Escola-Modelo Complementar e o Jardim da Infância" (Monarcha, 1999, p. 186). 
cientificamente distribuído de acordo com a posição enciclopédica das disciplinas", "harmônico em as suas partes", com o objetivo de uma formação integral e científica do normalista republicano (Ibid, p. 207). Entretanto, o pesquisador destaca igualmente as críticas de sua atuação:

Para alguns intérpretes do passado, o "currículo enciclopédico" configurado por Gabriel Prestes é incompatível com os objetivos do Curso Normal, na medida em que fornece ampla cultura geral e propedêutica em detrimento da fundamentação técnico-pedagógica, desvirtuando, assim, a formação do professor primário (Ibid, p. 213).

A presente análise não tem por objetivo problematizar a atuação de Gabriel Prestes no Curso Normal, e sim analisar a obra por ele escrita sobre o ensino de geometria. O interesse na figura de Prestes é discutir o seu papel de protagonista da institucionalização do processo de expertise, entendido como:

Uma instância, em princípio reconhecida como legítima, atribuída a um ou a vários especialistas - supostamente distinguidos pelos seus conhecimentos, atitudes, experiências -, a fim de examinar uma situação, de avaliar um fenômeno, de constatar fatos. Esta expertise é solicitada pelas autoridades do ensino tendo em vista a necessidade de tomar uma decisão. A solicitação de expertise, veremos, participa poderosamente da produção de novos saberes no campo pedagógico (Hofstetter et al, 2017, p. 57).

Certamente, vale destacar a importância política e social de Gabriel Prestes estar no comando de uma instituição reconhecidamente de referência. Para além disso, Hostetter et al (2017) destacam que os especialistas têm origem na própria docência em sentido amplo: inspetores, professores primários e secundário e diretores de escola. Eles são considerados "experts" pelo fato de que conhecem perfeitamente o ofício docente e nele se destacam: "A expertise é, portanto, realizada por pessoas do meio escolar, isto é, pela profissão docente. Nas condições institucionais claramente definidas, o trabalho de expertise se aperfeiçoa e desenvolve fortemente os saberes que lhe dizem respeito" (Hofstetter et al, 2017, p. 67-68, grifo nosso). A opção pelos conceitos de expert e expertise se dá pelo objeto da presente investigação: saberes geométricos para o ensino primário.

\section{O Ensino de Geometria e Gabriel Prestes}

Como diretor da Escola Normal da Praça, Gabriel Prestes publica o Manual Noções Intuitivas de Geometria Elementar ${ }^{9}$, em 1895, obra destinada a servir de guia aos professores primários interessados em buscar indicações práticas para o ensino. A publicação de uma obra escrita por Prestes com orientações ligadas à esfera da prática profissional docente e com referência aos saberes que a constituem, no caso, a geometria elementar intuitiva, reitera o seu papel de expert, no sentido atribuído por Hofstetter et al (2017). É preciso ainda considerar a complexa evolução das práticas de expertises no campo pedagógico, em especial no final do século XIX no Brasil, tempo das primeiras "expertises":

Pesquisas dos 'homens de bens' depois profissionais: numerosas e ricas, as primeiras 'expertises' aparentam de fato às pesquisas pontuais, aos métodos balbuciantes, iniciados ou confiados aos particulares que investem na missão de organizar uma instrução pública digna deste nome; as formas e as abordagens destas pesquisas se profissionalizam progressivamente enquanto se desenvolve o Estado responsável pela instrução pública; as premissas de um campo disciplinar se esboçam sobre esta base (Hofstetter et al, 2017, p. 104).

No prefácio do próprio autor, fica claro o contato de Prestes com obras estrangeiras, visto que inicia o manual com citação do livro de Clairaut ${ }^{10}$ e faz referência aos estudos de Eduardo Lagout e do matemático Dalsème ${ }^{11}$. No entanto, ao tomar contato com o livro Premiers Éléments de Géometrie Expérimentale appliquée à la mesure des longueurs, des surfaces et des volumes"12 de Paul Bert, publicado em 1886, Prestes abandona as ideias anteriores por considerar a obra como pertinente à leitura das crianças.

Paul Bert, então professor da Faculdade de Ciências de Paris, no prefácio de seu livro, constata o pouco gosto das crianças pela geometria, causado muitas vezes, pelos manuais que iniciam com uma interminável lista de definições sem interesse para a criança. E propõe, uma nova abordagem:

Eu vou direto ao objetivo, o objetivo do estudo da geometria nas escolas primárias não é o conhecimento das relações e propriedades das várias figuras ou volumes, mas a medida dos objetos que nos cercam. Então, esses objetos são de três ordens: linhas, superfícies, volumes ${ }^{13}$ (Bert, 1886, p. VII, tradução nossa).

Bert privilegia o enfoque de ensino a partir das medidas, de modo que na terceira ou quarta lição, a criança saiba como medir a altura de uma árvore ou de uma casa, e desta maneira possa obter um resultado útil, consequentemente tornandose interessada em seu estudo. As definições são apresentadas no caminho, o autor recusa os postulados de Euclides como ponto de partida e informa que a ordem de suas lições difere do que é convencionalmente utilizado.

O manual de Prestes para o ensino de uma geometria intuitiva trata-se de uma apropriação e não uma tentativa de traduzir a obra de Paul Bert, passo a passo. A filiação de Prestes em relação à proposta francesa identifica-se nos aspectos práticos das medidas, na crítica às definições, enunciados e demonstrações e também aos fatos concretos sem interesse

9 O livro faz parte do acervo Caetano de Campos. https://repositorio.ufsc.br/handle/123456789/159285

10 Sobre a tradução do livro Geometria de Clairaut, ver Valente (2000).

11 De acordo com Prestes, Lagout e Dalsème são considerados criadores do sistema taquimétrico.

12 "Primeiros elementos de Geometria Experimental aplicado as medidas de linhas, superfícies e volumes".

13 Je vais droit au but, eu le but de l'étude de la Géométrie dans les écoles primaires, ce n'est pas la connaissance des relations et des propriétés des diverses figures ou volumes, mais la mesure des objets qui nous entourent. Or, ces objets sont de trois ordres: les lignes, les surfaces, les volumes. 
real, de modo a atingir o seu propósito:

procurei fazer a aplicação prática dos preceitos estabelecidos, figurando-me, as mais das vezes, na posição do professor que tem deante de si uma classe de alumnos cuja attenção é preciso captivar, interessando-os pelo objeto das lições e cuja actividade intellectual é mister encaminhar logica e naturalmente, sem constrangel-a, mas tambem sem abandonal-a a si mesma (Prestes, 1895, p. 12).

O manual Noções Intuitivas de Geometria Elementar de Gabriel Prestes é publicado em São Paulo, pelo editor Horácio Belfort Sabino, destinado para o segundo ano das escolas preliminares e dedicado ao professor Dr. João Kopke ${ }^{14}$. Contém 95 páginas, distribuídas nos tópicos: Prefácio, Ordem a seguir na Geometria, Da linha reta, das curvas e ângulos, Da formação das linhas. Superfícies, Modo de fazer as recapitulações, Medida direta das superfícies, Superfícies curvas, Recapitulação abstrata, Diversos sólidos, Medida directa dos volumes e Conclusão.

Destaca-se, como já mencionado, que Gabriel Prestes estudou na Escola Normal de São Paulo entre 1886 e 1888 e assim, muito provavelmente, deve ter sido aluno do professor Godofredo José Furtado, um dos professores considerados como representante do positivismo na Escola Normal e titular das cadeiras de Aritmética e Geometria no período de 1883 a 1888. Um aluno dessa época publica, na Revista de Ensino, apontamentos tomados em suas aulas de Geometria. Valente (2011, p.44-48) analisa o material e conclui que:

Importa dizer, no entanto, que se trata de uma geometria dedutiva, onde a ordem das lições é aquela dos teoremas a serem demonstrados [...]. No que toca à Geometria, de modo diverso da indicação de Comte, a referência não são os estudos de medição de terras, colocados na Geometria de Clairaut que prevalecem. Novamente o discurso lógico-dedutivo toma o lugar do ensino dos temas geométricos, permeados pelas demonstrações dos diferentes teoremas da Geometria [...].

Pelas evidências e análises apontadas, a Geometria designada à formação dos professores primários na Escola Normal de São Paulo reveste-se de um caráter dedutivo e abstrato em contraposição às propostas normativas que deveriam acontecer nas práticas das escolas de primeiras letras: geometria prática, especialmente nas suas aplicações de superfícies e volumes. Neste sentido, é esclarecedor o relato de Prestes pela busca de obras estrangeiras e da pertinência do livro de Paul Bert como referência para sua produção. É importante também destacar que o século XIX é marcado pela circulação de ideias francesas na área da educação brasileira:

A necessidade de um embasamento científico para o desenvolvimento da educação faz com que os intelectuais brasileiros se apropriem das idéias de representantes da intelectualidade francesa para dar voz e força às idéias que consideram relevantes e significativas para serem implementadas (Bastos, 2000, p. 81).

A defesa de Prestes no que diz respeito à Geometria, pode ser lida desde o prefácio de seu manual. Segundo ele:

a Geometria é talvez de todas as sciencias a que primeiro se deve ensinar, porque as particularidades relativas á fórma e á grandeza dos corpos são indubitavelmente as que predominam nas observações espontâneas das creanças ao mesmo tempo que começam a formar a ideia de numero (Prestes, 1895, p.8).

Mesmo valorizando a importância do caráter abstrato da Geometria, o autor tece críticas a um ensino que parte de definições, princípios fundamentais e postulados ${ }^{15}$, por não serem compreensivos às crianças:

Mas a Geometria, pela natureza deductiva do seu methodo, só pode ser iniciada com proveito quando o espírito chegar ao grau de desenvolvimento preciso, quando a intelligencia adquirir a faculdade de abstracção necessaria para só considerar as propriedades geometricas e deduzir dellas todas as consequencias [...]. Como, pois, conciliar as exigencias deste ensino abstracto com a possibilidade de inicial-o desde logo nas escolas? (Prestes, 1895, p. 8).

Gabriel Prestes responde à questão da citação acima no seu primeiro tópico - Ordem a seguir na Geometria - em que ele propõe uma outra ordenação ao ensino da mesma ${ }^{16}$. Deve-se ressaltar que o manual foi elaborado para alunos do segundo ano da escola primária e no prefácio, o autor sugere que o primeiro ano seja "consagrado ao desenvolvimento da percepção pelo ensino intuitivo das fórmas geometricas, systema de Calkins ${ }^{17}$ ou de Prang" (Prestes, 1895, p. 12-13).

Segundo Prestes, os alunos são capazes de reconhecer as diversas espécies de grandezas e não apresentam dificuldade em distinguir uma linha, uma folha de papel e um copo. Ainda, de acordo com ele, a Geometria tem como finalidade, medir tais grandezas: linhas, superfícies e volumes

Assim, o objecto geral da Geometria, relativamente ás superfícies e aos volumes, é propriamente reduzir todas as comparações de superfícies e volumes a comparação de linhas. [...]. Fica, portanto, assentado como ponto de partida que as três grandezas que vamos estudar são assimilaveis e que a simples dimensão linear serve para caracterizal-a (Prestes, 1895, pp. 17-18).

Em síntese, o que está em questão são as grandezas e as respectivas medidas como elementares para o ensino de Geometria. Trata-se de atribuir para tais saberes - grandezas e

14 João Kopke torna-se divulgador do método analítico para o ensino da leitura no final do século XIX e início do século XX. Uma análise sobre seu trabalho pode ser lida em Warde e Panizzolo (2010).

15 Paul Bert, no prefácio de sua obra, também critica manuais que indicam em detalhes axiomas, considerando-os como de inutilidade absoluta e que reforçam a aprendizagem de cor. Além disso, tais manuais ainda consideram que se deva aprender o que é uma proposição, um teorema, corolário, todas palavras bárbaras, segundo o autor.

16 Uma vez mais, a alteração na ordem das lições segue em acordo com a proposta de Paul Bert.

17 Primeiras Lições de Coisas é o título de obra didática emblemática no processo de inovação pedagógica no final do século XIX no Brasil, escrito pelo norte-americano Norman Allison Calkins em 1861, traduzido e adaptado ao português por Rui Barbosa em 1886 . Um estudo mais aprofundado sobre o manual de Calkins pode ser lido em Frizarrini, Leme da Silva (2016). 
medidas - o lugar de início do ensino, de base para os estudos futuros e neste sentido compreende-se o destaque no primeiro tópico para a "Ordem a seguir na Geometria". Destaca-se ainda, a conformidade da proposta de Prestes com a defesa de Rui Barbosa pelo ensino elementar da geometria:

Não seria completa a base comum da educação geral, que a escola popular deve abranger em si, se depois de discernir, debuxar e modelar as combinações geométricas das linhas, superfícies e sólidos, o aluno não adquirisse certa preparação elementar no cálculo e medição delas. Para este fim introduzimos desde o segundo grau da escola a taquimetria. [...] A taquimetria é a concretização da geometria, é o ensino da geometria pela evidência material, a acomodação da geometria às inteligências mais rudimentares: é a lição de coisas aplicada à medida das extensões e volumes. [...] $\mathrm{Na}$ França a taquimetria ocupa fortemente a atenção dos conselhos centrais das administrações da agricultura, do comércio, da guerra, da marinha, da instrução pública. (Barbosa ${ }^{18}$, 1946, p. 290-291).

O manual de Gabriel Prestes advoga uma nova marcha no ensino ${ }^{19}$. Vale retomar que a proposta se refere ao segundo ano do ensino primário, considerando o estudo prévio das lições de formas segundo Calkins no primeiro ano, cujo objetivo é reconhecer semelhanças e diferenças entre as formas geométricas planas e espaciais, sem a intenção de que sejam definidas e formalizadas.

De acordo com Hofstetter e Schneuwly (2017, p.131-132), os saberes objetivados devem estar no centro das reflexões sobre as profissões do ensino e da formação, definindo para tanto "dois tipos constitutivos de saberes referidos a essas profissões: os saberes a ensinar, ou seja, os saberes que são os objetos do seu trabalho; e os saberes para ensinar, em outros termos os saberes que são as ferramentas do seu trabalho. Entende-se ainda os saberes objetivados como aqueles validados por um julgamento social:

Os saberes objetivados pertencem à zona semântica da cultura, das regras e dos valores, referem-se às realidades com o estatuto de representações ou de sistemas de representações que geram enunciados propositivos, sujeitos a um valor social aprovado por uma atividade de transmissãocomunicação. São conserváveis, acumuláveis, apropriáveis. Os saberes objetivados podem ser definidos como enunciados propositivos sujeitos a um julgamento social situado no registro de verdade ou de eficácia. (Barbier, 1996, tradução nossa).

O manual de Prestes pode ser interpretado como "um sistema de representações" para o ensino de noções intuitivas de geometria e busca através desta publicação o aceite pelos professores da época.

A proposta de mudança na ordem do ensino dos saberes de geometria indica uma nova geometria a ensinar, veiculada em obra assinada pelo diretor da Escola Normal. No entanto, o manual não inova somente na geometria a ensinar, mas igualmente, na orientação de como tais saberes devem ser mobilizados pelos professores, em outras palavras, apresenta um segundo sistema de representações que configuram os saberes para ensinar geometria.

Assim sendo, outra questão se coloca, como o professor deve apresentar ao aluno as noções de linha, superfície e volume? De acordo com a conceitualização de Hofstetter e Schneuwly (2017), quais são os saberes para ensinar tais noções? Para Prestes, a maneira como as mesmas são apresentadas não pode ser fornecida teoricamente e sim, intuitivamente, partindo do concreto como processo educativo. E, novamente, o autor reitera a crítica à ordem estabelecida nos compêndios de Geometria: estudo das linhas com todas as propriedades, em seguida das superfícies e por último, do volume.

Em confronto ao tido como marcha normal, Prestes justifica, uma vez mais, a proposta de mudança:

Neste primeiro ensino, porém, como já disse, há vantagem no confronto das três grandezas que se trata de estudar. Além disso o conhecido para a criança não coincide exactamente com o mais simples, porque o espirito infantil impressionado pelos objectos que o rodeiam adquiriu conjuntamente noções relativas ás linhas, ás superfícies e aos volumes (Prestes, 1895, p. 20).

A ordem estabelecida e, consequentemente a escolha dos elementares, saberes que constituem o início do ensino, pauta-se na concepção de educação. Alain Trouvé (2008) analisa a noção de saber elementar a partir de duas abordagens filosóficas: racionalista e empirista. Segundo o pesquisador, a pedagogia racionalista adota como centro as concepções de valores e ideias da razão e do saber, enquanto a pedagogia empirista privilegia a experiência e o sujeito. O autor também ressalta que a primeira abordagem, a racionalista, considera que o simples reside na abstração, enquanto que a segunda, a empirista, estima o simples na concretude.

Para pedagogia racionalista, o elementar e a ordem a ser seguida são determinados pela ciência de referência, no caso em questão, a lógica dedutiva da Geometria. Já a pedagogia empirista, o elementar e a marcha do ensino são fundamentados no indivíduo que aprende e na maneira como se dá a aprendizagem. A posição de Gabriel Prestes, em acordo com Paul Bert, ao propor o estudo conjunto de linhas, superfícies e volumes, leva em conta o espírito infantil e assim parece ser clara a adesão dos dois autores pela pedagogia empirista.

Para estruturar sua proposta, Prestes propõe uma nova abordagem para o ensino das medidas, distribuídas em:

18 As citações do parecer de Rui Barbosa sobre a reforma do ensino primário, de 1883, são referenciadas, no presente texto, considerando a edição das Obras Completas desse autor, volume X, Tomo II, publicadas em 1946.

19 No programa de 1894 do Estado de São Paulo, a matéria de Geometria está do $2^{\circ}$ ao 4 ano dos grupos escolares e o cálculo de área de figuras planas é indicado no $3^{\circ}$ ano e o volume no $4^{\circ}$ ano (Frizarrini, 2014). 
Quadro 1 - proposta de distribuição para o ensino de Geometria de Prestes

\begin{tabular}{|c|l|}
\hline $\mathbf{1}^{\mathbf{0}}$ ano & $\begin{array}{l}\text { Ensino intuitivo de formas geométricas de acordo } \\
\text { com Calkins ou Prang. }\end{array}$ \\
\hline $\mathbf{2}^{\mathbf{0}}$ ano & $\begin{array}{l}\text { Ideia geral das três grandezas - linhas, superfícies } \\
\text { e volumes; medida direta, feita por processos } \\
\text { espontâneos. }\end{array}$ \\
\hline $\mathbf{3}^{\mathbf{0}}$ ano & $\begin{array}{l}\text { Medida indireta das linhas, estudando por meio de } \\
\text { aplicações as suas propriedades principais, medida } \\
\text { indireta das superfícies e dos volumes deduzidos } \\
\text { a partir dos processos espontâneos estudados no } \\
\text { segundo ano. }\end{array}$ \\
\hline $\mathbf{4}^{\mathbf{0}}$ ano & $\begin{array}{l}\text { Medida indireta da circunferência, da área do } \\
\text { circulo, do volume dos corpos terminados por } \\
\text { superfícies curvas. }\end{array}$ \\
\hline
\end{tabular}

Fonte: Dados da pesquisa.

Prestes considera como medidas diretas realizadas por processos espontâneos os procedimentos práticos de comparação de um fio de tamanho de um palmo com as linhas a serem medidas, ou ainda, a cobertura de uma pedra a partir de quadrados de uma polegada quadrada. A experiência de práticas de medidas diretas com diferentes unidades e contextos subsidia a dedução das fórmulas, que ele designa por medida indireta. Pode-se evidenciar um caminho que parte de experiências concretas, por meio de cartonagem e recortes, para obter a sistematização abstrata das fórmulas de cálculo de áreas e de volumes. Vale ressaltar que Prestes não apresenta nem sugere nenhuma fórmula ou sistematização no manual proposto para o segundo ano. As medidas diretas (emprego de fórmulas) serão abordadas somente no terceiro ano ${ }^{20}$.

Mesmo na seção do manual intitulada Recapitulação abstrata, o autor sugere que os professores façam inúmeras perguntas sobre as atividades já estudadas, sem o concreto à vista das crianças. Por exemplo: Quantas espécies de linhas o menino conhece? Nas superfícies curvas pode-se ajustar a régua? Para medir o comprimento da linha precisa-se de um fio como o comprimento de um palmo, de uma polegada, não é? E para medir uma superfície plana? Entretanto, ao final, Prestes alerta para o caso de os alunos não conseguirem prosseguir sem a presença dos modelos concretos: "Se os alumnos não puderem responder, recorro novamente ás diversas figuras de madeira, caso que não se dará se o ensino tiver sido auxiliado constantemente pelo desenho" (Prestes, 1895, p. 73).

Pode-se dizer que a proposta de geometria intuitiva de Prestes traz uma marcha de ensino diferenciada, ao apresentar as grandezas e medidas como elementos iniciais para o ensino da geometria. Trata-se de uma nova organização de uma geometria a ensinar na escola primária brasileira, sustentada pela importância do conhecido para a criança, do espírito infantil impressionado pelos objetos que o rodeiam, de modo a "substituir" o mais simples do ponto de vista racional pelo mais compreensível para o aluno.
A proposta intuitiva de Gabriel segue direcionamento distinto do proposto pelos professores da Escola Modelo anexa à Escola Normal, que assinam o programa de $1894^{21}$. O mesmo se pode dizer da proposta do professor catedrático da cadeira de Geometria na Escola Normal, Godofredo Furtado. O fato de Prestes ocupar o cargo de diretor da Escola Normal, possivelmente indica sinais de conflitos e tensões, já mencionados por Monarcha (1999), na Escola Normal de São Paulo.

E como Gabriel Prestes apresenta em seu livro o desenvolvimento do estudo das linhas, superfícies e volumes, todos no $2^{\circ}$ ano do curso primário? Como o próprio autor ressalta, não é possível realizar uma abordagem teórica, é preciso expor e desenvolver tais noções intuitivamente.

Partindo das linhas retas, Prestes apresenta em conjunto o metro, a polegada, o palmo, a braça, o pé etc. e propõe que se discuta com os alunos como fazer a medida de uma linha, buscando comparações, dialogando com os alunos. Em seguida, faz a distinção entre linhas retas, curvas e quebradas, estabelecendo relação com os objetos da sala de aula. A próxima noção trabalhada é o ângulo, exibido como canto formado por duas linhas retas, apresenta o compasso, traça ângulos, mostra exemplos em que se identificam ângulos nos objetos da sala, trabalha com o ângulo reto em diferentes situações, mostra ângulos maiores e menores que o reto e adverte: "Que não se deve dar nem exigir definições com termos rigorosos exactos: pois é preferível indicar a denominação própria, ou fazer simples descrições" (Prestes, 1895 , p. 31). Todas essas propostas valorizam o ensino das medidas por meio do concreto e a da proximidade com a realidade das crianças, como o palmo dos meninos, o ângulo exemplificado nos objetos da sala.

A recapitulação, como Prestes denomina, a retomada dos assuntos anteriores antes de introduzir um novo conceito, é uma constante no livro, um saber para ensinar geometria. No entanto, há uma advertência sobre a revisão de estudos já realizados:

Cumpre notar que as recapitulações devem ser feitas de modo que não se tornem monótonas pela constante repetição dos mesmos exercícios: é preciso, ao contrario, que, mesmo recapitulando, o professor apresente sempre alguma idéa nova e que, nos exercícios que previamente preparar e escolher para a lição, não se sirva sempre dos mesmos objetos (Prestes, 1895, p. 42).

Assim, antes de apresentar a superfície, sugere-se a recapitulação das linhas e ângulos. A partir de uma régua e de uma prancheta, o autor explica o que vem a ser a superfície plana, sempre oferecendo outros exemplos da realidade do aluno.

20 Uma análise sobre a proposta de Gabriel Prestes para medida de área de paralelogramos presente no artigo intitulado Noções Intuitivas de Geometria elementar para o terceiro ano do ensino preliminar - Medida Indirecta das superfícies, publicada na Revista A Eschola Publica, em 1896 pode ser lida em Leme da Silva (2017).

21 Frizzarini (2014) analisa os programas de ensino do estado de São Paulo de 1894 a 1949/50. A medida de áreas e volumes (taquimetria) é proposta sempre nos anos finais dos grupos escolares (em geral, nos $3^{\circ} \mathrm{e} 4^{\circ}$ anos) na matéria de Geometria. 
O desenho é mais um saber para ensinar geometria apontado por Prestes como meio de despertar o interesse e captar a atenção dos alunos, ou seja, saberes mobilizados pelo professor como ferramentas do seu trabalho (Hofstetter et al, 2017). Sugere-se aos estudantes construir figuras de quadrados, losangos e retângulos, com a régua e esquadro, nas quais pode-se discutir as retas perpendiculares, oblíquas e paralelas.

Como exemplo, apresenta-se a orientação para a construção do quadrado:

Começo traçando no quadro negro uma recta que será a base do quadrado. Façam os alumnos o mesmo servindo-se das réguas. Em cada extremo da recta applico o esquadro e levanto perpendiculares. Façam os alumnos o mesmo servindo-se de esquadros de madeira ou mesmo cartão. Tomo em seguida um fio, ou a régua e marco o comprimento da base. Façam os alumnos o mesmo servindo-se de suas réguas ou de fios. Com o comprimento da base determino alturas eguaes nas perpendiculares. Eis graphicamente reproduzidas as diversas phases da operação indicada:

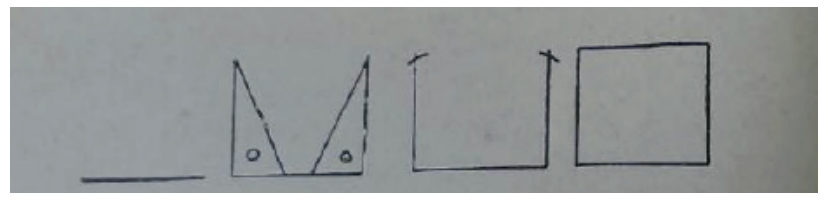

Concluido o desenho explico que a figura traçada chamase um quadrado (Prestes, 1895, p. 43-44).

O desenho do quadrado evoca aspectos relevantes no que diz respeito aos materiais: o uso somente de régua e esquadros, sem, no entanto, a obrigatoriedade de emprego da régua para medir, pois o autor indica a possibilidade do uso de um fio para marcar o comprimento da base e transportá-lo para as perpendiculares. A postura do professor é de conduzir no quadro as etapas do desenho proposto ao aluno, passo a passo. Ao finalizar, apresenta-se o nome da figura, sem a definição, mas convida os alunos a observarem suas características e propriedades. Vale também ressaltar, que Prestes sugere que os outros desenhos sejam produzidos em outras posições, de modo que o aluno não se habitue a uma posição só, como no caso do quadrado:

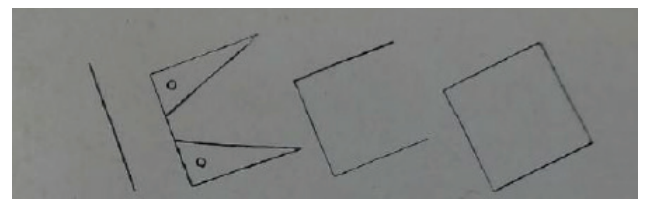

Prestes (1895, p. 49).

Sintetizando o emprego do desenho, Prestes esclarece que: "é executado advertir que estes exercícios têm o único intuito de facilitar as recapitulações e que, portanto, não podem dispensar o ensino de desenho a mão livre" (Prestes, 1895, p. 49).

A noção de superfície parte do recorte da construção de vários quadrados de uma polegada de lado para cobrir um retângulo, por exemplo. Discutem-se ainda as diversas possibilidades, como a situação em os quadrados não conseguem preencher toda a figura e a necessidade de outra unidade para completar.

Finalmente, Prestes (1895) apresenta os sólidos, inicia realizando o desenho do cubo com os alunos, parte do traçado de dois quadrados, que já foram realizados. Exploram-se primeiramente o cubo, as superfícies planas, número de faces, de arestas. Da mesma forma, ele analisa a pirâmide, cilindro, esfera. O autor desenvolve com mais profundidade os sólidos com superfície plana, iniciando novamente pelo cubo, que é formado por pedaços de arames e rolhas, assim como a planificação de alguns sólidos, como cubo, prisma, pirâmide.

O último tópico, antes das conclusões, é a medida direta dos volumes, em que Prestes (1895) inicia comparando um cubo a um paralelepípedo de mesma base, perguntando se tivesse que colocar os dois numa caixa, qual deles ocuparia maior lugar, para introduzir a ideia de maior volume. Depois reúne os cubos de cartão feitos pelos alunos (por meio da cartonagem) de modo a formar um cubo maior, explica que cada cubo pequeno é uma unidade cúbica e que o volume do cubo maior é o número de cubos menores que o formam. Fazse outros cubos com papelão e vai se explicando ao aluno as três dimensões do paralelepípedo, sem formalizar o conceito.

Nas conclusões, Prestes evidencia que a proposta não teve o propósito de criar um molde inflexível, do qual o professor não possa se afastar. Ao contrário, sua intenção foi de "indicar os pontos que, perante a lógica, parecem essenciais, e que ao professor, servirão de advertencia para methodizar o seu ensino" (1895, p. 94).

A postura de Prestes em não propor um modelo rígido para o desenvolvimento da geometria intuitiva indica singularidade, haja vista que o período em questão, de circulação e divulgação da pedagogia moderna, do método intuitivo, é caracterizado pela historiadora Marta Carvalho (2000) pela arte de ensinar, cujo segredo é a boa imitação de modelos. Segundo a autora, a lógica do ensino centra-se no exercício escolar, as revistas estruturam-se como caixas de utensílios para uso dos professores, com seções de prática compostas por roteiros ou modelos de lições. Em verdade, Prestes (1895) apresenta um conjunto de modelos que podem ser empregados na sala de aula, sempre guiados pelo professor, mas, deixa a cargo do professor a escolha, organização e combinação das lições.

Outra singularidade de Prestes no que diz respeito ao manual para o ensino de geometria é abraçar uma proposta francesa em contraponto com a formação recebida na Escola Normal de São Paulo pautada de um caráter dedutivo e abstrato em Geometria.

Em síntese, identifica-se na proposta de Prestes (1895) a ausência de definições, a preocupação em exemplificar os conceitos discutidos com objetos da realidade do aluno, a presença de instrumentos de apoio, papel, recortes, construção de sólidos, o desenho com régua e esquadro como uma contribuição importante na compreensão dos conceitos, 
configurando-se em acordo com a proposta pautada no método intuitivo, de exploração e diálogo com o professor. Configura-se, desta forma, uma proposta inovadora na escolha e organização dos saberes a ensinar, assim como na maneira que mobiliza saberes para ensinar, com sugestões e indicações.

Até o momento, não foi possível encontrar outros livros publicados por Gabriel Prestes e sim uma coleção de três artigos de sua autoria publicados na Revista A Eschola Publica no ano de 1896. Os artigos destinam-se ao terceiro ano do curso preliminar, no qual o autor retoma as considerações do livro e desenvolve atividades para a introdução das medidas indiretas (fórmulas para cálculo de áreas e volumes).

\section{Conclusão}

A análise da proposta para o ensino de geometria no segundo ano escolar de Gabriel Prestes fornece indícios de proposta inovadora: proximidade com a proposta francesa de Paul Bert (1886), inversão na marcha dos conteúdos tradicionalmente apresentados ao propor um estudo direto das medidas de linhas, áreas e volumes, uso de materiais como fios, barbantes, papelão, recortes de papel, construção de sólidos para um trabalho experimental, de comparação e discussão das medidas, o emprego do desenho à mão livre como auxiliar nas recapitulações. Tudo indica que uma proposta como tal, no final do século XIX, tenha se revelado como inovadora, diante de uma pedagogia tradicional, pautada em definições e memorizações.

Entretanto, justamente no momento da publicação de uma proposta inovadora do ensino de geometria, o papel de liderança atribuído a Prestes sofre transformações bruscas, que o levam a se distanciar das questões educacionais:

Apartirde 1895, mudanças nas orientações políticas, Gabriel não dispõe mais de amplo incentivo e apoio governamental. Em 1898, descontente com a nova regulamentação da instrução pública e as críticas à organização do Curso Normal, Prestes retira-se da direção da escola Normal da Praça, distancia-se do ensino público, mergulhando em uma fama brumosa - as iniciativas de Prestes são confundidas com as de Caetano de Campos (Monarcha, 1999).

A perda de poder político e o afastamento de Gabriel Prestes da Educação são fatores que corroboram para que a sua proposta de uma geometria intuitiva não tenha feito escola, haja vista que o estudo das áreas de superfícies e volumes de sólidos manteve-se até meados do século XX nos anos finais do curso primário do Estado de São Paulo, $3^{\circ}$ e $4^{\circ}$ anos escolares (Frizzarini, 2014). A nova ordem pregada pelo manual, que corresponde a mudanças nos saberes a ensinar não foi objetivada nas normatizações oficiais do estado de São Paulo.

Mesmo sem evidências de que o manual tenha se tornado referência, é relevante examinar seu caráter inovador na ordem dos saberes a ensinar, ao tomar como ponto de partida, as medidas de comprimento, superfície e volumes desde o segundo ano escolar. Do mesmo modo, a proposta de uma nova abordagem para o estudo de tais saberes, como a medida direta, ou seja, de forma intuitiva e com recursos distintos, como a recapitulação dos conceitos estudados, por meio do desenho à mão livre, pode ser lida como ferramenta para o ensino em questão, ou, nos dizeres de Hofstetter et Schneuwly (2017), saberes para ensinar geometria.

As ferramentas mobilizadas na proposta de Prestes, os saberes para ensinar geometria podem ser identificados nos programas do século XX, porém não atrelados especificamente ao ensino das medidas, nem mesmo à matéria de Geometria. Os materiais didáticos empregados no manual como recortes, construção de sólidos fazem parte da matéria Trabalhos Manuais como a cartonagem e no programa de 1925 passam a ser inseridos na matéria Formas destinada somente ao primeiro e segundo anos do grupo escolar, em que se lê: "Nada de definições ou noções abstratas. Da observação dos sólidos é que se deve chegar ’a concepção das ideias de superfície, ângulo, linhas, etc. Bem compreendidas essas noções, faremos toda a classe representar formas estudadas por meio do desenho e reproduzi-las em barro ou cartolina" (São Paulo, 1925). No entanto, o estudo das medidas de áreas e volumes encontram-se separados, nos terceiros e quartos anos, na matéria de Geometria.

Outro saber para ensinar geometria, o desenho à mão livre, também não ganha relevância nas normativas. Ao contrário, a partir do programa de 1918, o desenho inserido na Geometria recomenda "traçados de linhas com uso do compasso" (São Paulo, 1918) no $3^{\circ}$ ano. A matéria de Desenho propriamente, a partir do século XX, vai dar destaque para o método de ensino do desenho ao natural, se distanciando das figuras geométricas.

Para Hofstetter et al. (2017), a institucionalização da expertise não é um processo linear, se realiza por etapas, pelos avanços e retrocessos, conjugando momentos de dependência forte, orientados por gestores técnicos e outros aonde a expertise se automatiza parcialmente e torna-se aliada da mudança.

Reitera-se que a institucionalização da expertise participa poderosamente da produção de novos saberes no campo pedagógico, porém seu processo de legitimação, de reconhecimento por seus pares é longo, complexo e conflituoso. Apesar da posição de destaque ocupada por Gabriel Prestes e da importância da Instituição dirigida por ele, considerado como um expert em educação no final do século XIX, a sua proposta de ensino não faz escola. Como dito antes, o período pode ser considerado como de primeiras expertises, de "métodos balbuciantes" e que se profissionalizam progressivamente em parceria com o Estado. Por esta ótica, a saída de Gabriel Prestes da direção da Escola Normal da Praça e do ensino público corrobora para que as noções intuitivas de uma geometria elementar não tenham ganho legitimidade no período. 


\section{Referências}

Barbier, J. M. (1996). Savoirs Théoriques et savoirs d'action. Presses Universitaires de France.

Barbosa, R. (1946). Reforma do Ensino Primário e várias Instituições Complementares da Instrução Pública. Obras Completas de Rui Barbosa. Vol. X. 1883, tomo II. Rio de Janeiro: Ministério da Educação e Saúde.

Bastos, M. H. C. (2000). Ferdinand Buisson no Brasil - Pistas, vestígios e sinais de suas idéias pedagógicas (1870-1900). História da Educação, (8),79-109.

Bert, P. (1886). Premiers Éléments de Géometrie Expérimentale appliquée à la mesure des longueurs, des surfaces et des volumes. Paris: Librairie CH. Delagrave.

Carvalho, M. M. C. (2000). Modernidade pedagógica e modelos de formação docente. São Paulo em Perspectiva, 14(1), 111120 .

Chervel, A. (1990). História das disciplinas escolares: reflexões sobre um campo de pesquisa. Teoria \& Educação, 2, 177-229.

Frizzarini, C. R. B. (2014). Do ensino intuitivo para a escola ativa: os saberes geométricos nos programas do curso primário paulista. Dissertação (Mestrado em Educação e Saúde) Universidade Federal de São Paulo, Guarulhos.

Frizzarini, C.R.B, \& Leme da Silva, M.C. (2016). Saberes geométricos de Calkins e sua apropriação nos programas de ensino dos grupos escolares paulistas. Revista Brasileira de História da Educação, 16 (3), 10-35.

Hofstetter, R., \& Schneuwly, B. (2017). Saberes: um tema central para as profissões do ensino e da formação. In: R., Hofstetter, W.R. Valente, W. R. (Org.). Saberes em (trans)formação: tema central da formação de professores, (pp.113-172). São Paulo: Livraria da Física.

Hofstetter, R., Schneuwly, B., Freymond, M., Bos, F. (2017). Penetrar na verdade da escola para ter elementos concretos de sua avaliação - A irresistível institucionalização do expert em educação (século XIX e XX). In: R., Hofstetter, W.R. Valente. Saberes em (trans)formação: tema central da formação de professores (pp.55-112). São Paulo: Livraria da Física.

Leme da Silva, M.C. (2017). Ensino de Medidas: final do século XIX e início do século XXI. Anais da $38^{\text {a }}$ Reunião Anual da ANPEd.
Leme da Silva, M.C., Trindade, D.A., D’Esquivel, M. O., \& Oliveira, M. A. (2017). A matemática dos primeiros anos escolares e a circulação do método intuitivo nos manuais escolares. In: W.R. Valente, I.M. Abreu. A matemática dos manuais escolares: curso primário, 1890-1970. São Paulo: Livraria da Física.

Monarcha, C. (1999). Escola Normal da Praça: o lado noturno das luzes. Campinas: Editora da UNICAMP.

Prestes, G. (1895). Noções intuitivas de geometria elementar. São Paulo: Editor Horacio Belfort Sabino.

São Paulo. Trecho do decreto n. 2.944, de 8 de agosto de 1918. Aprovado por Altino Arantes e assinado por Oscar Rodrigues Alves. Disponível em: <https://repositorio.ufsc.br/ handle/123456789/99555>. Acesso em 10 out., 2013.

São Paulo. Trecho do programa de 19 de fevereiro de 1925. Aprovado pelo secretário de Estado dos Negócios do Interior, José Manuel Lobo. Disponível em: <https://repositorio.ufsc. br/handle/123456789/99651>. Acesso em 10 out., 2013.

Souza, R.F. (2009). Alicerces da pátria: História da escola primária no Estado de São Paulo (1890-1976). Campinas: Mercado de Letras.

Trouvé, A. (2008). La notion de savoir élémentaire à l'école. Paris: L'Harmattan.

Valdemarin, V. T. (2004). Estudando as lições de coisas: análise dos fundamentos filosóficos do Método de Ensino Intuitivo. Campinas: Autores Associados.

Valente, W. R. (2000). Positivismo e matemática escolar dos livros didáticos no advento da República. Cadernos de Pesquisa, 109, 201-212.

Valente, W. R. (2011). A Matemática na formação do professor do ensino primário: São Paulo, 1875-1930. São Paulo: Annablume.

Valente, W. R. (2015). A constituição do elementar matemático: uma análise de programas de ensino (São Paulo, 1890-1950). Educação Unisinos (Online), 19, 196-205.

Vidal, D. G. (Org.). (2006). Grupos escolares: cultura escolar primária e escolarização da infância no Brasil (1893-1971). Campinas, SP: Mercado das Letras.

Warde, M. J.; Panizzolo, C. (2010). As fontes do método analítico de leitura de João Kopke (1896-1971). História da Educação, 14(30), 127-151. 